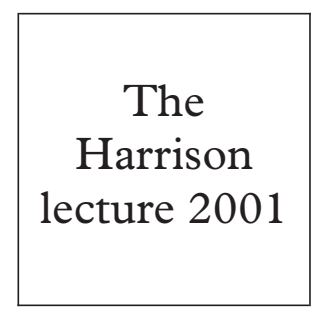

R N T Thin

\author{
R
}

\title{
Clinical governance and genitourinary medicine
}

\section{Introduction}

This paper will briefly outline Harrison's contribution to venereology or genitourinary (GU) medicine, and show how his principles of good practice fulfil many of the principles of clinical governance. The paper will then outline some general principles of clinical governance and indicate how they relate to GU medicine.

\section{Colonel LW Harrison, CB DSO MBCHB FRCPE}

Harrison's early career was in the Royal Army Medical Corps. Here, he undertook general duties (general practice), clinical venereology, and laboratory work in which he demonstrated a flair for research and development. In the first world war he showed enormous organisational and administrative ability by setting up a venereology service for the British Army in north west Europe based on a hospital with 3000 beds. By the end of the war he was adviser in venereology to the War Office.

He retired from the army in 1919 at the age of 43 years. The same year he was appointed adviser in venereology to the Ministry of Health and set up a model clinic at St Thomas's Hospital in London. His principles for the design of a clinic were:

(1) Waiting periods were to be kept to a minimum

(2) Patients should be examined in the greatest possible privacy and never in the presence of other patients

(3) Ease of access of staff to patients

(4) The distances covered by staff and the time occupied in obtaining drugs and instruments should be kept to a minimum.

These principles still apply. Waiting periods were minimised by keeping his clinic open for 12 hours a day on weekdays and for nearly as long on Saturdays and Sundays.

He had written guidelines for the content of case notes, including the source of infection, and guidelines for treatment. He reviewed the case notes of all patients for quality and the relation between the clinical features and laboratory results. He discussed any problems with the doctors concerned. Thus, in his clinical practice he fulfilled three aspects of clinical governance-namely written guidelines, audit, and (informal) appraisal. He was an enthusiastic teacher and was one of the first to introduce cine films into undergraduate teaching. $\mathrm{He}$ held a weekly clinical meeting for clinic staff and students in which he discussed selected cases. He was a founder member of the Medical Society for the Study of Venereal Diseases
(MSSVD) and took an active part in its meetings. He was a founder editor of the society's journal and held office for 17 years. He made many contributions to the literature. Thus, he was a strong supporter of what he would have regarded as postgraduate education, now embraced by continuing medical education (CME) and continuing professional development (CPD). As adviser to the Ministry of Health at a time when many towns and cities were setting up clinics in accordance with the Public Health (Venereal Diseases) Regulations 1916, he visited many departments and provided advice - a form of peer review. He therefore saw clinical excellence arising from written guidelines, audit, appraisal, $\mathrm{CME} /$ CPD, and peer review. If one changes the terminology, Harrison's view of good practice or clinical excellence fulfilled many facets of the concept of clinical governance. Fuller details of Harrison's life were described by $\mathrm{Mr}$ Ambrose King in the first Harrison Lecture. ${ }^{1}$

Early in 1919 Harrison was invited to Edinburgh to become lecturer in venereal diseases and to set up a clinic. ${ }^{1} \mathrm{He}$ did not take up this appointment as he accepted the post of adviser in venereology to the Ministry of Health in London, but he maintained contact with Edinburgh. Harrison's work caught the attention and imagination of senior figures in Edinburgh medicine. Harrison was elected to the membership of the Royal College of Physicians of Edinburgh in 1919, and in 1924 he became a fellow of the college. On both occasions he was supported by senior fellows at the very top of the college hierarchy (Iain Milne, college librarian, personal communications) and the leaders in medicine at Edinburgh where clinical excellence has always been held in high regard.

\section{Clinical governance}

By the mid 1990s, the National Health Service in the United Kingdom had become more financially driven than ever before, with chief executives of trusts having financial control as their prime responsibility. Around this time there were a number of well publicised clinical failures. Towards the end of the decade, the government of the day decided to change the emphasis to the quality of clinical care. Various methods of monitoring clinical standards, such as clinical guidelines, audit, and model job descriptions were in place, but were not coordinated and did not work well. The concept of clinical governance was introduced to draw these together and provide a focus for raising the quality of care. ${ }^{2}$ Clinical governance provides a system or framework for many 


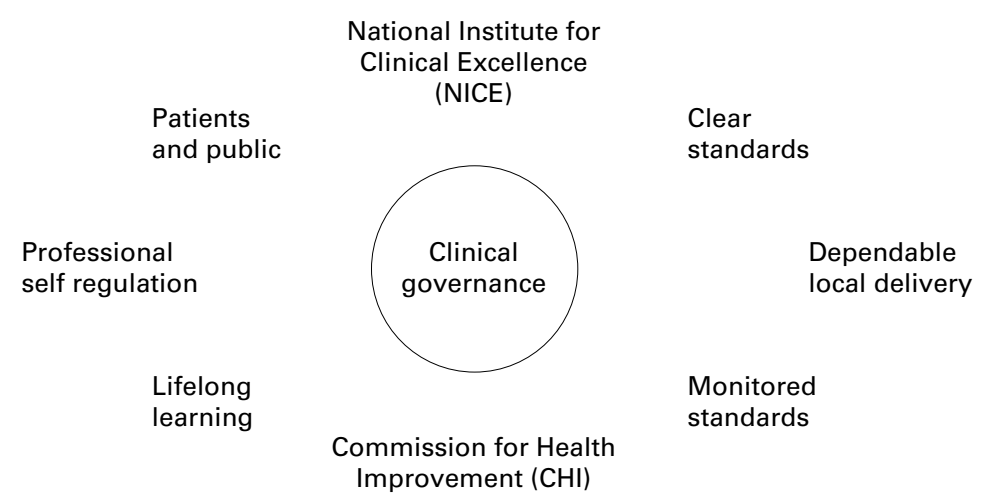

Figure 1 Clinical governance is at the centre of the many activities contributing to excellence which are currently under revision; these provide standards against which clinics can audit their practice. ${ }^{4}$ The Association for GU Medicine (AGUM) has also produced standards and guidance for other aspects of clinic activity, ${ }^{5}$ and it is likely that in future more standards and guidelines will be needed. For a number of areas of clinical activity, national service frameworks (NSFs) have been drawn up which describe standards for service delivery, ${ }^{2}$ but as yet none of these involve GU medicine.

COMMISSION FOR HEALTH IMPROVEMENT

Another new organisation is the Commission for Health Improvement (CHI). This body's role is to monitor delivery of service by routinely reviewing every organisation every 4 years, to undertake special investigations when something has gone seriously wrong, to conduct studies of NSFs, and provide leadership to promote best practice. ${ }^{2}$ The role of GU medicine is to take part when the commission reviews trusts. which every member of staff strives for quality. Many of the activities encompassed by the concept of clinical governance are local. To emphasise its importance, the final responsibility for quality is placed with the chief executive of every NHS organisation though its delivery is delegated to a senior clinician, often the medical director. Clinical governance is overseen by a subcommittee of the board but, to work, there must be ownership by all staff. ${ }^{2}$

The three main principles underpinning clinical governance are demonstrable:

(1) Clear standards of service

(2) Dependable local delivery

(3) Monitoring of standards of local delivery. ${ }^{2}$

Many activities are required to fulfil these principles and clinical governance is at the centre, coordinating and drawing them together. Some of the activities are long established such as audit, while some new organisations have been set up such as the National Institute for Clinical Excellence (NICE), ${ }^{2}$ and some established processes further developed such as professional self regulation and $\mathrm{CME} /$ CPD. The different activities are shown in figure 1 . Though it was foreseen that many of the processes would take time to develop their full potential, early in 2001 many were established to varying degrees and will be considered in turn.

NATIONAL INSTITUTE FOR CLINICAL EXCELLENCE The National Institute for Clinical Excellence (NICE) was set up to appraise new and existing health technologies or interventions, to develop clinical guidelines, and to promote their audit. NICE has taken over the management of the four national confidential inquiries. It has set up six collaborating centres to take forward multidisciplinary development of guidelines ${ }^{3}$; GU medicine is a participant in the Collaborating Centre for Women and Children. In addition, GU medicine has demonstrated its quality standards for service provision by submitting its national management guidelines,

\section{PATIENT AND PUBLIC INVOLVEMENT}

The NHS has long had lay (namely, public) representation at the board level of its organisations. A lay representative is required on clinical standards and governance committees. Lay people are mandatory on research ethics committees which should not meet unless these members are present. ${ }^{6}$ The emphasis now is that the patient must be at the centre of NHS activity and that the public should have much greater input to the NHS at all levels. Patients and public must therefore be involved in many aspects of clinical governance. ${ }^{2}$ As well as helping to plan and monitor services, patients, users, carers, and the public should be involved in activities such as audit, planning research, and sitting on research and development committees.

Patients now expect to be involved in making decisions about their care and this is well recognised in GU medicine. Human immunodeficiency virus (HIV) units have encouraged patients and carers to discuss provision of services informally and through patient satisfaction surveys. Some HIV clinics have user groups and these could provide participants for focus groups to discuss aspects of service provision. ${ }^{7}$ More use could be made of HIV and other community based groups. Some HIV clinics have open evenings and these could be a focus for more user liaison. There has been less patient participation in sexually transmitted infection (STI) clinics and more is needed. Most STI clinics undertake patient satisfaction surveys and these could be expanded to include accompanying people. In depth interviews could be undertaken with some attendees to explore problems like access. ${ }^{8}$ Open evenings could be held for STI patients; there is probably more scope for involving these patients than is recognised. Patients taking part in drug trials usually cooperate very enthusiastically and those with warts may be frequent attendees; these patients might form a nucleus 
of users willing to collaborate more in discussion of service provision.

Involving patients and public in discussing provision of GU medicine will be challenging and interesting, and should provide ideas to improve our service. For example, with the current problems of access, it is easy to say that improved funding will solve the problem. At present there is a national shortage of nurses and other staff, so money alone may not be the solution. Patients may have useful views on improving access and, for example, on the management of chronic recurrent conditions such as herpes and warts.

PROFESSIONAL SELF REGULATION

This remains important in ensuring and monitoring dependable service delivery. There are two main divisions. The first concerns the General Medical Council (GMC). This body currently ensures that all doctors wishing to practise in the United Kingdom are suitably qualified for entry on to the general medical and specialist registers. The council is the final professional organisation for assessing and disciplining underperforming doctors. It provides guidance in publications on good medical practice, ${ }^{9}$ and is currently developing a process of periodic revalidation to satisfy itself that doctors remain up to date and eligible to remain on the registers. ${ }^{10}$

The second form of self regulation which also assists in ensuring and monitoring dependable local service delivery concerns personal responsibilities. All clinicians must take part in audit, some of which involves their personal clinical practice. All doctors should now have personal job plans. The British Medical Association and Royal College of Physicians have templates of job plans for consultants in GU medicine. ${ }^{11}{ }^{12}$ Job plans should be reviewed every year at an annual appraisal undertaken by a trained colleague who may be the clinical director. This is under implementation for consultants but is not yet in place for non-consultant career grades. At the annual appraisal consideration is given to the job plan, the facilities and services available, and the consultant's strengths, weaknesses, and aspirations. The work load, CME/CPD, and personal development are reviewed. Personal development includes any special training the consultant needs or would like, while the trust may wish training to be undertaken, for example, in a new technique to enhance the service. The appraisal will cover the consultant's research, publications and presentations, clinical management, and committee work. In the final part of appraisal the job plan for the ensuing year is agreed. Appraisal is confidential and conversations need to be positive and candid to be useful and successful..$^{5101314}$

The latest guidance from the NHS prescribes the documentation to be used to record appraisal. ${ }^{14}$ It is proposed that this documentation will provide the basis of the paperwork needed for revalidation by the GMC. Revalidation will be based on an independent review of this documentation every five years. ${ }^{10}$
The third activity is peer review where a department or service is reviewed by a group of specialists in the same field but working in other trusts. This concept is supported by the Royal College of Physicians and has been well developed in other specialties. Hitherto, because of financial constraints, it has been invoked in GU medicine only when services have had problems. The Association for GU Medicine is taking forward discussions to develop a rolling programme of visits. ${ }^{5} 1516$

Though these activities may appear daunting at first sight, they are common in many large organisations and are helpful to the organisation and to individual staff members.

The Association for GU Medicine is looking at ways to support colleagues, especially single handed consultants and those in nonconsultant career grades-for example, in preparing for appraisal and peer review. Peer review will assist in resolving problems that cannot be cleared up during appraisal, and AGUM hopes to able to offer support to help colleagues and services. ${ }^{5}$ If problems cannot be resolved during appraisal and peer review, a GU medicine support review could be requested by trusts before they consider calling in the Royal College of Physicians who also offer clinical service reviews ${ }^{16}$ or the Commission for Health Improvement. ${ }^{2}$ It is hoped that by these processes the specialty will be able to help to resolve problems at an early stage.

LIFELONG LEARNING

CME has long been recognised as vital to maintain and enhance clinical standards. In the past doctors often took part in postgraduate education in an unstructured manner with variable benefit to their practice. Now CME/ CPD and personal development must relate more to the needs of the individual and the organisation. $^{2}$

For the past 5 years there has been a voluntary system of registration and notification of CME/CPD activities monitored by the royal colleges. In 2001 a more formal scheme was introduced. In planning CME/CPD, the physician's clinical and other activities need to be considered including future aspirations and the need to obtain the necessary credits. ${ }^{17}$

RISK AVOIDANCE AND RISK MANAGEMENT

In 2000 it was realised that in the NHS as a whole there were more untoward incidents affecting patients than previously recognised. ${ }^{18}$ Risk avoidance and risk management assist in their reduction. Many of the activities already considered contribute to risk avoidance and risk management. Other processes, which apply to all healthcare workers, include the ability to change practice when this is needed, something doctors sometimes find difficult. All healthcare workers need to be able to recognise and know what to do when things go wrong in their own practice and that of colleagues. Systems are required for incident and near miss reporting, complaints procedures need to be seen to lead to change and, when things do go wrong, organisations need to move from a "blame culture" to a learning and training culture. ${ }^{2}$ 


\section{Key messages}

- Clinical governance coordinates activities that improve quality. When Harrison established venereology/genitourinary medicine, his principles of good practice such as guidelines, internal audit and (informal) appraisal fulfil modern clinical governance

- The patient must be at the centre of NHS activity and more discussion with users and the public may indicate ways to improve services

- Colleagues, especially single handed consultants, may benefit from the support of the specialty when preparing for annual appraisals and, in due course, revalidation

- Many specialties are developing rolling programmes of external peer review of all departments. GU medicine is looking at ways to develop the current reactive peer review into a programme of visits, and to support a service with problems to help to resolve these at an early stage
GU MEDICINE

In many respects GU medicine has been abreast or ahead of the developments outlined and takes pride in this. The specialty was founded on an ethos of multidisciplinary team working. Though clinical governance is a local matter, GU medicine already has many systems in place that can be applied locally. There is a tradition of guidelines for clinical management which is being maintained and these provide clear standards. Monitoring delivery is well established with internal departmental audit, multidisciplinary trust audits, and regional GU medicine audits. The specialty has set in train mechanisms to work with trusts on professional self regulation and to provide support for colleagues in their job plans and appraisal. Clinics already have many systems in place for risk avoidance and risk management; these must be carefully monitored so that confidentiality is maintained but not abused. Peer review must be worked up into a system respected by trusts and the specialty, with the option of additional support reviews if these will assist in the early resolution of difficulties. Postgraduate training is adapting to provide $\mathrm{CME} / \mathrm{CPD}$, and the specialty's leaders will need to continue to be sensitive to changing needs.

Probably the major challenge for the specialty lies in increasing patient and public involvement in advising on service delivery, audit, and research. The input already in place in HIV units needs to be enhanced and form a model to develop similar contributions to STI clinics. This will require sensitive handling to maintain trust and confidentiality. Successful working with patients and the public could help to solve some problems including quick simple self referral or access, and to secure adequate financial resources.

\section{Conclusion}

Harrison set up the specialty on a firm foundation of clinical excellence that fulfils many of the latest requirements. He would have been thrilled to see how the specialty has broadened and would have applauded the drive for excellence. However, he might have been concerned over the burgeoning literature on clinical governance, reminded us that the pursuit is excellence of clinical care for the patient, and that clinical governance must not become an end in itself. The bottom line must always be; is clinical care improving?

This paper is based on the Harrison Lecture presented at the Spring Meeting of the Medical Society for the Study of Venereal Diseases in May 2001 at Belfast.

1 King A. The first Harrison Lecture. $B r f$ Vener Dis 1974;50:391-403

2 National Health Service Executive. Clinical governance: quality in the new NHS. HSC 1999/065. London: Department of Health, 1999.

3 Rawlings R. In pursuit of quality:the National Institute for Clinical Excellence. Lancet 1999;353:1079-82.

4 Clinical Effectiveness Group. UK national guidelines in sexually transmitted infections and closely allied conditions. Sex Transm Inf 1999;75:Suppl 1.

5 Association for Genitourinary Medicine. Clinical governance in GU medicine. 2001.

6 National Health Service Management Executive. Local National Health Service Management Executive. Local
researcs committees, HSG(91)5. London: Department of Health, 1991. identify and resolve problems. 
7 Tozer M. Learning from the patient experience: evaluating service quality from the perspective of patients and carers.

Clinical Governance Bulletin 2000 ;

8 Foley E, Patel R, Green N, et al. Access to genitourinary medicine clinics in the United Kingdom. Sex Transm Inf $2001 ; 77: 12-14$

9 General Medical Council. Good medical practice. 2nd ed. London: GMC, 1998

10 General Medical Council. Revalidating doctors: ensuring standards, securing the future. London: GMC, 2000.

11 British Medical Association. NHS duties of a consultant in genitourinary medicine. London: BMA, 1999.

12 Royal College of Physicians. Consultant physicians working for patients. London: RCP, 1999.

13 Johnson C, Leigh J, Lloyd S, et al. Consultant peer appraisal. A structured system to support clinical governance and revalidation. Clinical Governance Bulletin 2000;1 No 2:12-13.

14 Department of Health. Consultant's contract: annual appraisal for consultants, $A L(M D)$ 5/01. Leeds: DoH, 2001.

15 Association for Genitourinary Medicine. Peer review process, 1995.

16 Ward J. Risk management and substandard clinical care. $\mathcal{F} R$ Coll Phys Lond 2000;34:478-80.

17 Royal College of Physicians. New CPD system for physicians 2001: planning, recording and evaluating educational activities. London: RCP, 2001

18 Secretary of State for Health. An organisation with a memory. London: DoH, 2000

19 Mayor S. NHS introduces new patient safety agency. BMF 2001;322:1013.

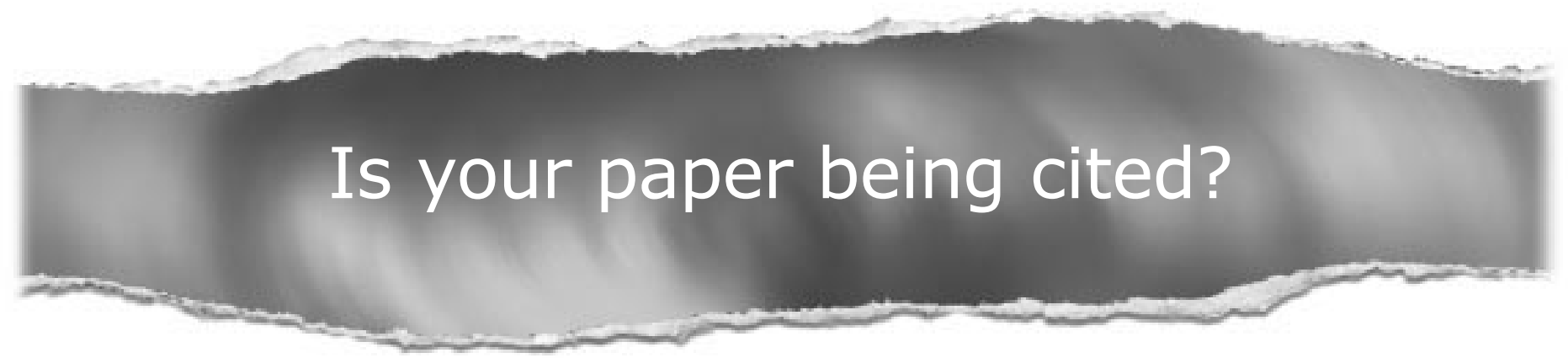

CiteTrack service

CiteTrack will alert you by email whenever new content in Sexually Transmitted Infections or a participating journal is published that matches criteria you want to track

Topics: Tell CiteTrack which words or subjects to watch for in new content

Authors: Be alerted whenever key authors you are following publish a new paper

Articles: Know whenever a paper of interest to you is referenced by another paper

\section{www.sextransinf.com}

